\title{
触感のよいぬいぐるみロボットの手足のための 柔軟な糸駆動機構の提案
}

\author{
Proposal of Flexible String Actuation Mechanism for Arm and Leg \\ of Stuffed Animal Robot with Good Sense of Touch
}

\author{
○椎名 美奈（電通大）＼cjkstart長谷川 晶一（電通大）
}

Shiina MINA, The University of Electro-Communications, shiina@hi.mce.uec.ac.jp Shoichi HASEGAWA, The University of Electro-Communications

\begin{abstract}
This work proposes mechanism of stuffed animal robot having friendly face and soft sense of touch, that wants to touch by person and becomes it. Today, the robot that cohabits with man is actively researched. As the one, the stuffed animal loved by a lot of people regardless of the age, sex or the country was paid to attention. The stuffed animal robot of this research achieves seeming the stuffed animal it by softening the moving part. The actuator is brought together at the center of the stuffed animal robot's body. Its arm and leg consist of only soft such as cloth, cotton and sponge. The actuator is driven with string.
\end{abstract}

Key Words: Stuffed Animal Robot, Good Sense, Flexible, String Actuation Mechanism

\section{1. はじめに}

近年，家庭や公共施設などで人間と同居し，人間とコミュ ニケーションを行いながら，物理的作業支援を行う人間共棲 ロボットの研究が盛んに行われている。こうしたロボットは, 長時間人間の傍で働くという特徵を持つため, 安全性以外に 人間に対して親和的な印象を与えることが重要となる。そこ で本研究では，人間共棲口ボットを考えるにあたり，生活の 中で存在に違和感がなく, 触りたくなるという特徽を持つ「ぬ いぐるみ」に着目した．ぬいぐるみは，動物や特定のキャラ クターなどをかたどった布を縫合し，綿などを内部に詰めた もので，老若男女，国を問わず多くの人に受け入れられてい る。ぬいぐるみの材料である布は，毎日人間が身につける衣 服にも用いられていることから，人間にとって安心感や心地 よいという感情を与えることができる素材であると言える. つまり，その布を使ったぬいぐるみは，人間に対し外見の親 和性と触った時の安心感を与えることのできる姿であると考 えられる。柔らかい妨ぐみのような外見をしたロボット として, 東京大学の関口らによって開発された RobotPHONE[1] や，産総研の柴田らによって提案されたメンタルコミットロ ボットPAR0[2]などが挙げられる。これらのロボットは柔らか い妨る゙るみのような外見をしているにも関わらず，触り心 地は硬く，柔らかいぬいぐるみのイメージを崩している.

そこで本研究では，触り心地のよいぬいぐるみロボットを 実現するために，硬い部分を最小限にし，可動部に生地や綿

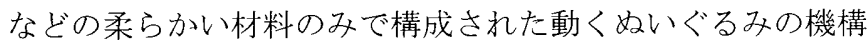
を提案する.

\section{2. ぬいぐるみロボット}

\section{1 㽖動方法}

ぬいぐるみの駆動方法として，系駆動を採用した。系駆動 とは糸によるワイヤ駆動のことで, 可動部が軽量かつ柔軟, またアクチュエータを駆動部から遠い位置におけるという特 徵がある。これを用いることで，可動部の柔らかい触感を実 現できる。

\section{2 可動部の構造}

今回目標とする動きを

・腕を上げる（手を振る）

・腕を曲げる（物を抱える）

- 手先のみ動かす（握手する）

とした。使用する材料は一般的にぬいぐるみを製作する際に 使用される材料である系，布，綿，スポンジ，ビーズを使用 する．駆動の要である系には，切れにくく摩擦が少ないとい う特徵を持つ高密度ポリエチレンの釣り糸を使用する。詰め 物としては綿とスポンジを用いる。綿とスポンジはともに柔 らかい素材であり，その特徵として復元力がある，それぞれ を比較した結果，ば水定数は綿に比べスポンジの方が大きい という傾向がみられた．腕の動きを考えるために，この詰め 物の復元力を考慮し, 腕の構造のモデルを図 1 (a)のように仮 定した.

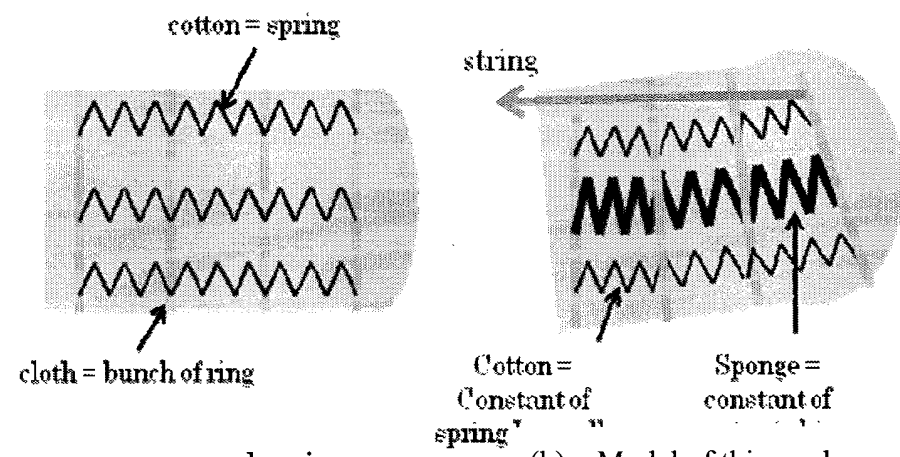

(a) Model of basic

(b) Model of this work

Fig.1 Model of stuffed animal's arm

これは，腕の筒形状をリングの集合とみなし，そのリング の間を複数のばねが繋いでいる。このモデルから，部分的に ば衫定数の違う材料にすることで腕の性質を変えることがで きると考え, 図 $1(\mathrm{~b})$ のような構造を考えた. 中心のウレタン スポンジを綿で囲み，その表面に糸を這わせる構造で，ばね 定数の大きなば称の周りをば称定数の小さなば衫で囲んでい 
るような状態である．中心のスポンジは周りの綿に比べ復元 力が大きいため，系を引いた時に腕全体が縮んでしまうのを 防ぐ役割をしている。このモデルから目標とする動きを実現 する系の配置を図 2 のように決定した，手先を曲げる糸の配 置は，手先部分は腕を曲げる系の配置と同じように腕の内側 を配置し，腕を曲げたい位置で糸を中心部分に入れる。この ように配置すると糸を引いた時，糸は一直線になろうとする ため, 系が中心に向かって腕を横断している部分の詰め物が 縮み, この部分で曲がる.

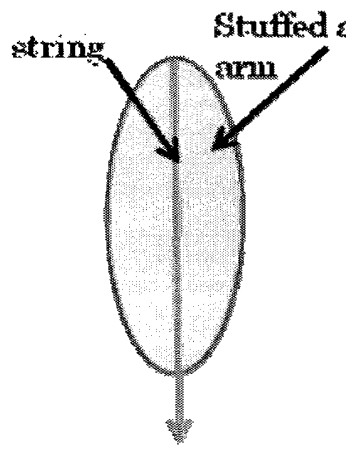

(a) hands up

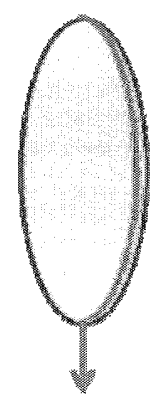

(b) flex

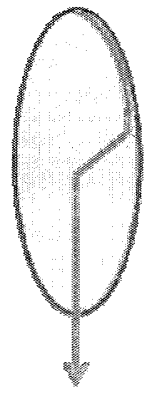

Icl joint
Fig.2 Design of string

さらに，他の要素も含めた腕の構造を図 3 のようにした。 組み立てのしやすさを考慮し，袋の中に詰め物を入れ，その 外側に系を這わせるようにした。本稿ではこの袋を綿袋と呼 ぶ，系が綿袋の中央を通る部分については，綿袋の中央のス ポンジに切り込みを人れ，糸をサテン生地で巻いてから通し ている。これによりスポンジと糸の摩擦を軽減することがで

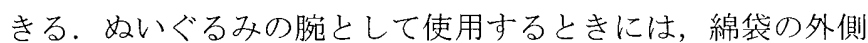
に半透明の生地を被せ，さらにその外側を奴るみの毛皮 で覆う。半透明の生地は綿袋の糸の位置を目で見て調整しや すくするためのものである。また，可動部は綿など軽い材料 を使用しているため，腕の先端におもりとしてビーズ入れ， 腕を重力方向の初期位置に戻しやすくした.

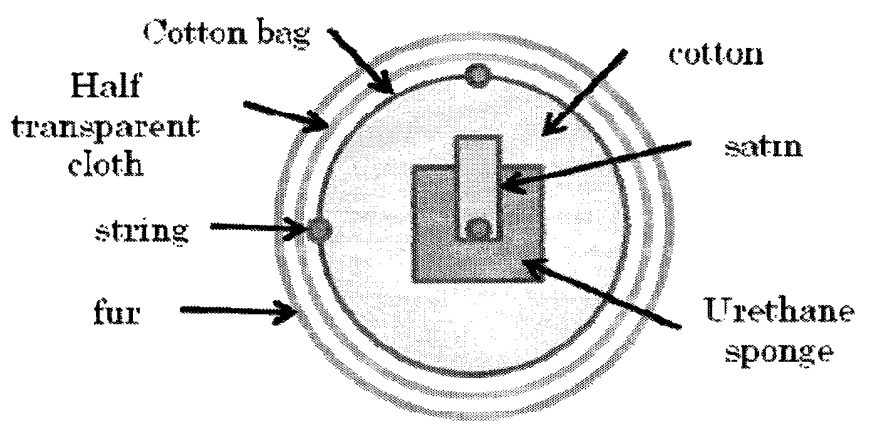

Fig. 3 Cross section of cotton bag

\section{3 アクチュエータとセンサ}

本研究で提案するぬいぐるみロボットは硬い部分を最小限 にするため, アクチュエータなどは全て体幹部に集約したい.

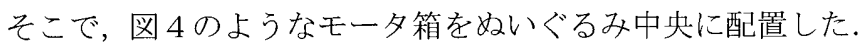

モータ箱内のモータには糸が巻かれたプーリとガイドがつい ており，このモータを回転させることでぬいぐるみの腕の糸 の長さを変化させる，モータは自作のモータマウントでモー 夕箱に固定されている．また，今回選定したモータはギアが 固く逆可動性がないため，ぬいぐるみの腕を人が触るなどし て外力が加わった時, モータに付属のエンコーダの出力から はそれを知ることができない，そこで，モータマウントに溝 を作り，糸がモータに加える力によって溝の距離が変化する ようにした。この距離の変化をフォトリフレクタという発光 素子と受光素子が一体となったセンサで計測し，モータにか かる力を測定できるようにした。フォトリフレクタによる距 離計測の原理は以下の通りである。

まず，溝にはスポンジを挟んでおく．フォトリフレクタの 発光部から出た光はスポンジによる拡散により回り込みフォ トリフレクタの受光部に入る.モータマウントに力が加わる と, 溝の距離が短くなりスポンジが潰され, 回り込む光の量 が減り, フォトリフレクタの出力が変化する.

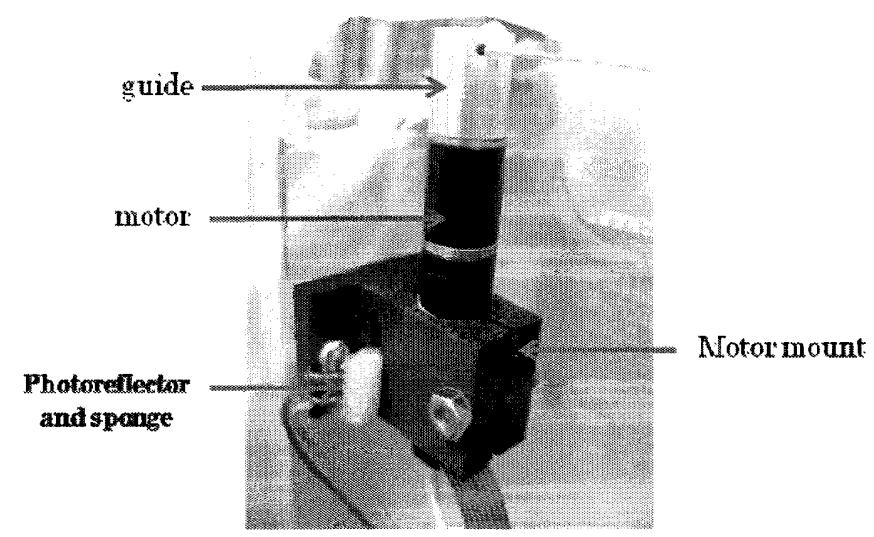

Fig.4 Actuator and sensor fixed stuffed animal's body

\section{3. 実験}

前章で提案した機構を用いて腕が動くめいぐるみを製作し た. 今回はイワヤ株式会社より販壳されているクマの妨ぐ るみ型ロボットIPRobotPHONE の外装を使用してぬいぐるみ を製作した。

\section{1 動作実験}

決定した糸の配置で目標とする動きが実現できるかどうか を検証した。

ぬいぐるみの腕を上げる糸（モータ 1) と腕を曲げる糸（モ 一タ 2）の 2 本の糸の長さを変化させて，三角形を描くよう に腕を動かした．図 5 に始ぐるみの様子を, 図 6 にそのと きの糸の長さの変化を示した. 図 6 の動作 1 から 2 で腕を曲 げ，動作 2 から 3 で腕を曲げた状態で上に挙げ，動作 3 から 5 で腕を元の位置に戻した。図 5 より，ぬいぐるみの腕が二角 形を描くことができたといえる.

また，手先のみ動かすための糸の長さを変化させ，目的の 動作が実現できるかどうか確かめた。このときの結果を図 7 に示す，図からわかるように，可動部には関節になるような 硬い要素がないにも関わらず，肘から腕を曲げたかのような 動きが実現できた。 


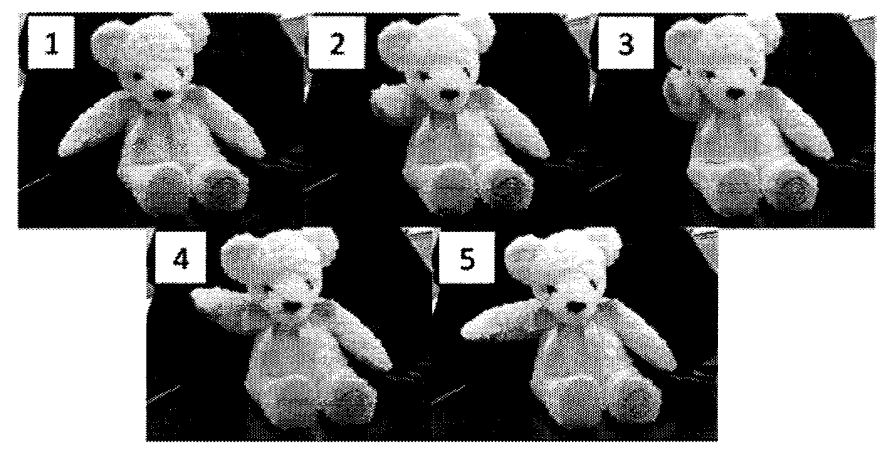

Fig. 5 Stuffed animal's arm draft triangle

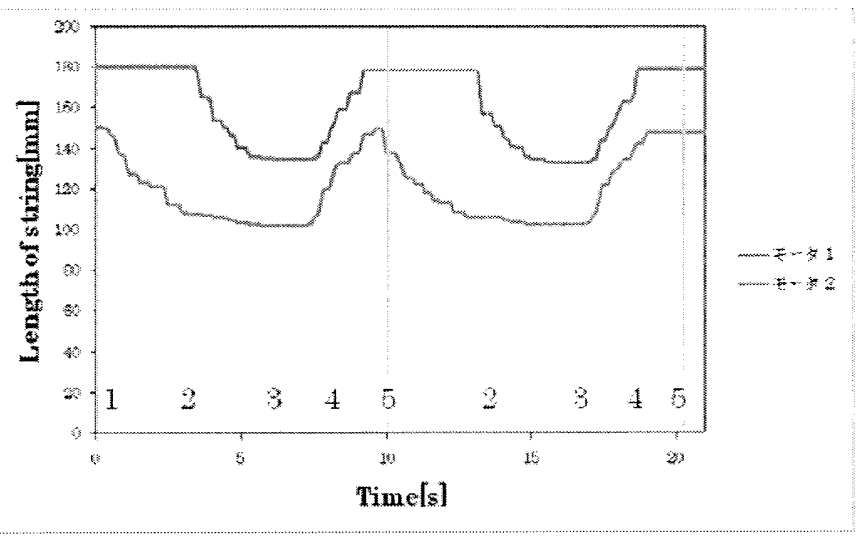

Fig.6 Length change of string to draft triangle

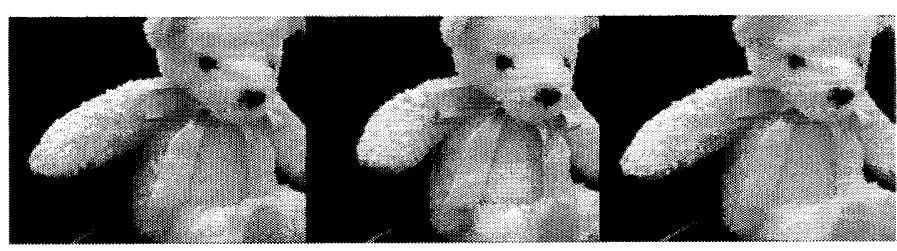

(a) Initial condition

(b)bended

(c) return

Fig.7 Stuffed animal flex arm

\section{2 カセンサ実験}

今回提案したカセンサシステムでぬいぐるみの腕に人が力 を加えたことを検出できるかを調べた．ぬいぐるみが腕を上 げる途中で腕を下に向かって押した.これを 3 回繰り返し, 人が力を加えなかった時と加えたときのセンサからの出力電 圧を比較した。その結果を図 8 に示す.腕を触った時の出力 電圧の方が腕に力を加えなかったときに比べ大きいのが分か る.このことからこのセンサは人が力を加えたこと検出でき ると言える。

\section{3 触り心地の評価実験}

本研究で提案したぬいぐるみが触り心地が良いと判断され るかをアンケートにより調べた，用意しためいぐるみは，柔

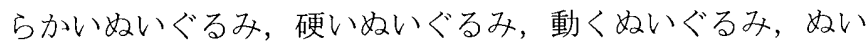
ぐるみ型ロボット, 本研究の奴くるみの 5 種類で, 女性 3 人，男性 5 人の計 8 人に対して調查を行った. 結果を図 9 に
示す。この図から，本研究で提案したぬいぐるみは全ての被 験者に 2 位または 3 位に選ばれたことがわかる。これより， 今回提案しためいぐるみは駆動装置が入っているにも関わら ず触り心地がよいと判断された。また，硬いぬいぐるみとぬ いぐるみ型ロボットの結果に注目すると結果が 1 位から 5 位 に分散している。このことから，ぬいぐるみに対しての好み は人により大きく異なるということも言える。

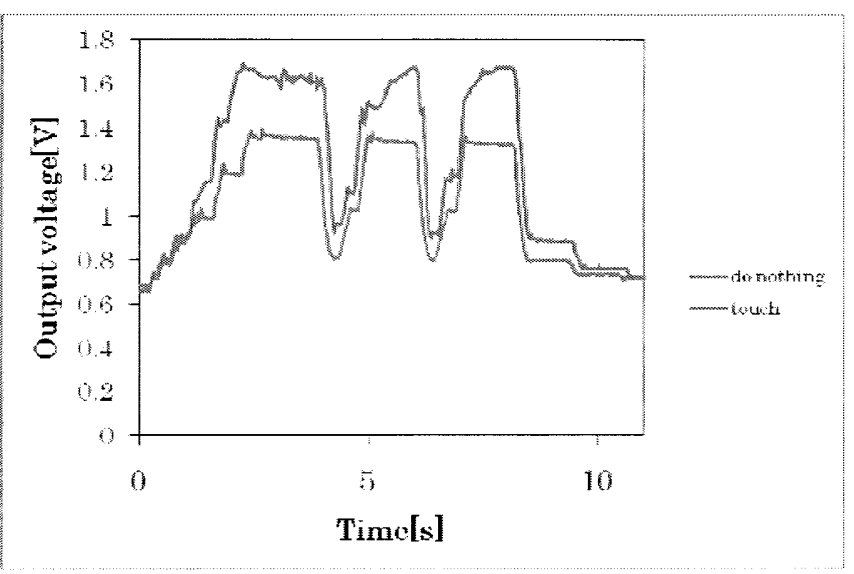

Fig.8 Output voltage of sensor

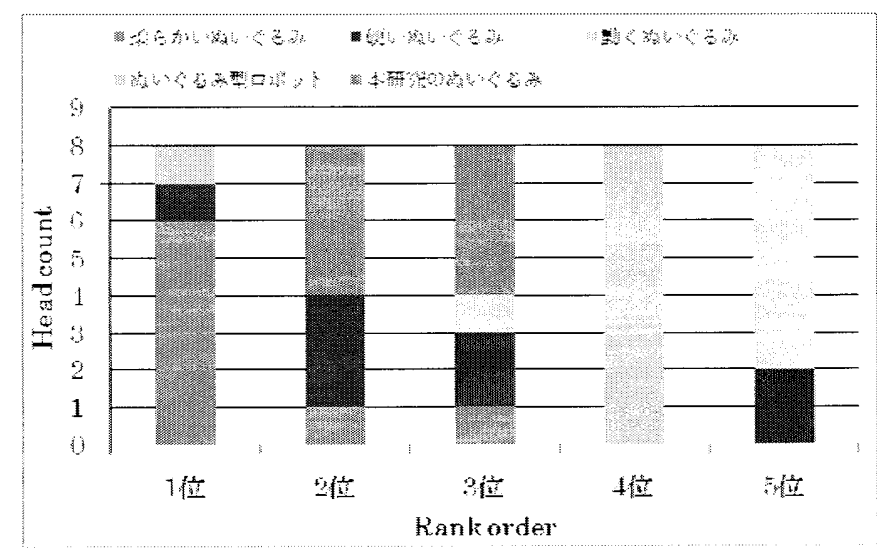

Fig.9 Questionnaire conclusion

\section{4. おわりに}

本研究では, 触感のよい奴゙るみロボットのための機構 を提案し，その要素である糸駆動による動きとカセンサの評 価を行った，そして，本研究で提案するぬいぐるみロボット が人によい触感である感じさせる可能性があることを示した。

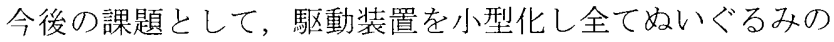
中に収め, ワイヤレスな如ぐるみロボットを完成させ，こ のぬいぐるみロボットが人を癒す相棒のようなロボットにし ていきたい.

\section{文 献}

[1] Dairoku Sekiguchi, Masahiko Inami, Susumu Tachi,RobotPHONE: RUI for Interpersonal CommunicationCHI 2001,Extended Abstracts, pp. 277-278, 2001

[2] Takanori Shibata, An Overview of Human Interactive Robots for Psychological Enrichment, PROCEEDINGS OF THE IEEE, Vol.92, No.11, pp1749-1758, 2004 